\title{
Depression and chronic pain in the elderly: links and management challenges
}

\author{
This article was published in the following Dove Press journal: \\ Clinical Interventions in Aging \\ 21 April 2017 \\ Number of times this article has been viewed
}

\section{Panagiotis Zis' \\ Argyro Daskalaki \\ Ilia Bountouni ${ }^{3}$ \\ Panagiota Sykioti ${ }^{3}$ \\ Giustino Varrassi ${ }^{4}$ \\ Antonella Paladini ${ }^{5}$}

'Academic Department of Neurosciences, Sheffield Teaching Hospitals NHS Foundation Trust, Sheffield, UK; ${ }^{2}$ Department of Neurology, Evangelismos General Hospital, Athens, Greece; ${ }^{3}$ Belgrave Liaison Team, Child and Adolescent Mental Health Services, South London and Maudsley NHS Foundation Trust, London, UK; ${ }^{4}$ Fondazione Paolo Procacci and European League against Pain, Rome, ${ }^{5}$ Department of MESVA, University of L'Aquila, L'Aquila, Italy
Correspondence: Giustino Varrassi c/o Fondazione Paolo Procacci, Via Tacito 7, 00I93 Roma, Italy Email giuvarr@gmail.com

\begin{abstract}
Aging is an inevitable process and represents the accumulation of bodily alterations over time. Depression and chronic pain are highly prevalent in elderly populations. It is estimated that $13 \%$ of the elderly population will suffer simultaneously from the two conditions. Accumulating evidence suggests than neuroinflammation plays a critical role in the pathogenesis of both depression and chronic pain. Apart from the common pathophysiological mechanisms, however, the two entities have several clinical links. Their management is challenging for the pain physician; however, both pharmacologic and nonpharmacologic approaches are available and can be used when the two conditions are comorbid in the elderly patients.
\end{abstract}

Keywords: depression, chronic pain, elderly, neuroinflammation, cognitive impairment, pain

\section{Introduction}

Aging is an inevitable process and represents the accumulation of bodily alterations over time. ${ }^{1}$ These changes include both somatic and emotional maturity; however, many pathologic processes also occur as part of the aging process to the point that the latter is among the greatest risk factors for most diseases. ${ }^{2}$

The emotional burden of the accumulated negative experiences might lead to depressed mood, which although might just be a normal reaction to events such as bereavement, it can also be a feature of depression. ${ }^{3}$ The end-of-life development of depressive symptoms has been thoroughly investigated, ${ }^{4}$ and it is unanimously accepted that depression is the most prevalent and the most treatable mental health problem in old age. ${ }^{5}$ Apart from its major emotional impact, depression can atypically also cause somatic symptoms such as fatigue. ${ }^{6}$

Chronic pain, on the other hand, has many similarities with depression in old age. Chronic pain is common; although it is predominantly a somatic symptom, it might also have a detrimental emotional element. Indeed, pain is a universal experience and the human body's most valuable alerting system. ${ }^{7}$ According to the International Association for the Study of Pain, it is defined as an unpleasant sensory and emotional experience associated with actual or potential tissue damage, or is described in terms of such damage. ${ }^{8}$ Recently, also because chronic pain is not perceived anymore as a simple symptom but as a disease in its own right, there is increasing interest in the relationship between this disease and the modifications of the nervous system. ${ }^{9}$ Apparently, many other diseases of elderly people seem to be part of the same process of general "chronification". Many of the researchers interested in gerontology, but also in neurology and pain, are convinced that the common pathogenic factor would be neuroinflammation.

This comprehensive review of the current literature aims to explore the clinical links between chronic pain and depression and also to discuss the management challenges 
for the clinician when the two conditions are comorbid in the elderly patients. It will also analyze in depth the potentiality that neuroinflammation could represent the common element that put together the two pathologies: pain and depression.

\section{Phenomenology and diagnostic challenges Depression versus mild cognitive impairment}

Depression is a leading cause of disability worldwide and a major contributor to the overall global burden of any disease. ${ }^{10}$ The World Health Organization estimates that $\sim 350$ million people suffer from depression, while over 800,000 people die because of suicide every year. ${ }^{11}$

According to the Diagnostic and Statistical Manual of Mental Disorders, Fifth Edition, a diagnosis of a major depressive disorder requires presence of symptoms such as depressed mood, sleep cycle disturbances, fatigue and poor concentration for at least 2 weeks, causing clinically significant distress or impairment in social functioning. ${ }^{12}$ However, occult depressive-like behaviors remain a challenge to the clinician, especially because such behaviors are often manifestations of an underlying premature cognitive dysfunction.

Mild cognitive impairment (MCI) describes the gray zone between a normal cognitive function and dementia. Individuals with MCI can also experience difficulties in memory, language, thinking skills or judgment (4AD). ${ }^{13}$ These difficulties, however, are not severe enough to interfere with daily life or independent functionality. The National Institute on Aging-Alzheimer's Association defines MCI as the change in cognition reported by the patient or clinician, as well as objective evidence of impairment in one or more cognitive domains with preserved functionality. ${ }^{14,15}$

More than often, apathy, withdrawal and self-neglect are the first symptoms of MCI. Patients with neurodegenerative diseases, including MCI, have a difficulty in reporting their symptoms accurately. For example, instead of reporting or being able to recognize the feeling of sadness, they might present with anxiety. ${ }^{12}$ Similarly, assessment of pain in people with dementia is particularly challenging because of the loss of communication ability, which limits the subjective reporting of pain that would normally be expected with cognitively healthy adults. ${ }^{16}$

The relationship between depression and cognitive dysfunction is very complicated and not well decoded so far. Indeed, symptoms and clinical presentation often overlap, so clinicians face a challenging decision when it comes to choosing the appropriate treatment strategy.

\section{Types and causes of chronic pain in the elderly}

The distinction between acute and chronic pain is often determined by an arbitrary interval of time since onset, with the most commonly used marker being 3 months from its first appearance. ${ }^{17}$ Further classification of pain is based on the clinical characteristics and etiology.

\section{Neuropathic pain, nociceptive pain and mixed pain definitions}

A broad categorization of pain which is useful in clinical practice is nociceptive and neuropathic pain. Nociceptive pain is the pain that arises from actual or threatened damage to non-neural tissue and is due to the activation of nociceptors, while neuropathic pain is defined as the pain caused by a lesion or disease of the somatosensory nervous system. ${ }^{18}$ However, not uncommonly, chronic pain is the result of both neuropathic as well as nociceptive mechanisms and can be classified as a mixed pain syndrome on these occasions. ${ }^{19}$

\section{Causes of chronic pain in the elderly}

A clinically useful categorization of pain syndromes based on the underlying etiology is the one proposed in the new version of the International Classification of Diseases, Eleventh Revision, according to which pain syndromes can be classified into seven groups: ${ }^{17}$

1. Chronic cancer pain: is caused either directly by the cancer (primary tumor invasion or metastases) or indirectly by the treatment (ie, chemotherapy-induced neuropathy and radiotherapy). ${ }^{20}$

2. Chronic neuropathic pain: is caused by any lesion in the somatosensory nervous system (ie, thalamic stroke, peripheral neuropathy and radiculopathy). Neuropathy is highly prevalent in old age, ${ }^{21}$ and common causes of painful neuropathies include diabetic neuropathy, ${ }^{22}$ alcoholrelated neuropathy, ${ }^{23}$ gluten neuropathy ${ }^{24}$ and entrapment neuropathies. ${ }^{25}$ However, up to one-third of neuropathies, which can be painful as well, will remain idiopathic (of unknown etiology) despite extensive investigations. ${ }^{26}$

3. Chronic musculoskeletal pain: arises as part of diseases directly affecting the bones (ie, fractures), joints (ie, inflammatory and degenerative arthritis), muscles (ie, myositis) or related soft tissues (ie, tendonitis). Occasionally, chronic musculoskeletal pain can indirectly arise as part of diseases, because of bad posturing (ie, Parkinson's disease)..$^{27-30}$

4. Chronic post-traumatic or postsurgical pain: is a definition by exclusion, when other causes of pain as well as a 
Table I Pain syndromes, major causes and types of pain

\begin{tabular}{|c|c|c|}
\hline Pain syndrome & Etiology & Type of pain \\
\hline Chronic primary pain & Unknown & $\begin{array}{l}\text { Difficult to distinguish the type } \\
\text { (ie, fibromyalgia, irritable bowel syndrome) }\end{array}$ \\
\hline Chronic cancer pain & $\begin{array}{l}\text { Directly caused by the tumor (ie, bone metastases) } \\
\text { Related to treatment (ie, postsurgical, } \\
\text { chemotherapy related, radiotherapy related) }\end{array}$ & $\begin{array}{l}\text { Visceral, musculoskeletal and neuropathic } \\
\text { Usually neuropathic }\end{array}$ \\
\hline $\begin{array}{l}\text { Chronic postsurgical and } \\
\text { post-traumatic pain }\end{array}$ & $\begin{array}{l}\text { Definition of exclusion; other causes (ie, infections) } \\
\text { and pre-existing pain need to be excluded }\end{array}$ & $\begin{array}{l}\text { Usually purely neuropathic or with a } \\
\text { neuropathic component }\end{array}$ \\
\hline Chronic neuropathic pain & $\begin{array}{l}\text { Stroke, peripheral neuropathy, radiculopathy and } \\
\text { cranial neuralgias }\end{array}$ & Neuropathic \\
\hline Chronic visceral pain & Inflammation, ischemia and obstruction & Nociceptive \\
\hline \multirow[t]{2}{*}{ Chronic orofacial pain } & Cranial neuropathies (ie, trigeminal neuralgia) & Neuropathic \\
\hline & Temporomandibular disorders & Nociceptive \\
\hline Chronic musculoskeletal pain & Arthritis, fractures and myositis & Nociceptive \\
\hline
\end{tabular}

pre-existing pain syndrome are excluded and the patient suffers from pain that has developed after a surgical operation or a traumatic lesion. ${ }^{17}$

5. Chronic visceral pain: is a predominantly nociceptive pain which originates from the internal organs, commonly because of inflammation (eg, chronic pancreatitis), ${ }^{31}$ ischemic lesions (ie, chronic mesenteric ischemia) ${ }^{32}$ or obstruction (ie, bowel obstruction). ${ }^{33}$

6. Chronic headache and orofacial pain: This subcategory includes chronic headaches, which are not further discussed in this review, as the aim of this paper is to focus on the chronic-bodily pain and orofacial pain syndromes. The latter can be purely neuropathic secondary to cranial neuropathies (ie, trigeminal neuralgia) ${ }^{34}$ or predominantly nociceptive secondary to temporomandibular disorders. ${ }^{35}$

7. Chronic primary pain is a pain syndrome that cannot be explained by another chronic pain condition. In this category, syndromes such as low back pain, ${ }^{36}$ identified as neither musculoskeletal nor neuropathic, can be found, as well as painful conditions causing significant emotional distress, such as irritable bowel syndrome and fibromyalgia. ${ }^{37}$

Table 1 summarizes the pain syndromes, their major causes and their pain characteristics.

\section{Epidemiology}

\section{Epidemiology of depression in the elderly}

In $2015,12.3 \%$ of the world population consisted of people aged 60 or over. ${ }^{38}$ This percentage will almost double by 2050 as by then, $21.5 \%$ of the world population will consist of people aged 60 or over. ${ }^{38}$ This percentage increased further to $32.8 \%$ in the more developed regions. ${ }^{38}$ Because of this and the increased life expectancy, numerous studies focusing on the epidemiology of the diseases of the aging population have been conducted.

Current estimates vary significantly from $4.3 \%$ in China ${ }^{39}$ to $63 \%$ in Korea. ${ }^{40}$ These figures, though, should be interpreted with extreme caution, as the gold standard for diagnosing depression is not similar since some studies use only screening questionnaires ${ }^{40-44}$ while other studies use proper psychiatric interviews. Also, there is a significant selection bias of the studied population, as some studies have been conducted in nursing homes, ${ }^{45}$ rehabilitation environment, ${ }^{42}$ inpatients ${ }^{46}$ or community. ${ }^{39,40,47,48}$

In a recent meta-analysis focusing on the prevalence of depression, Volkert et $\mathrm{al}^{49}$ estimated that the lifetime prevalence of major depression in people 50 years or older in the western countries is $16.5 \%$. Solhaug et $\mathrm{al}^{50}$ conducted a prospective cohort study and showed that the incidence of depression increases with age. This is one of the elements that make clear a relationship between at least some of the chronic pathologies of the elderly.

Although the prevalence varies significantly across countries and different elderly populations, the majority of studies concluded that depression in the elderly is highly associated with poorer cognitive status, ${ }^{47}$ higher number of medical problems, ${ }^{39,48,51}$ more severe disability ${ }^{44,52}$ and lower socioeconomic status. ${ }^{44}$

\section{Epidemiology of chronic pain in the elderly}

The prevalence of chronic pain in the general population shows high variability mainly because of the differences across the studied populations and the methodology of the studies. ${ }^{53}$ Heterogeneity in prevalence is also secondary to variable definitions of pain chronicity. ${ }^{54}$ Over the last years, the methodology has improved significantly, as the studies are 
now population based (with the participants being representative of the general population), the duration criterion has been set to be pain of at least 3 months duration and the presence of pain and its characteristics has been evaluated by validated questionnaires. Based on these population studies, ${ }^{55-72}$ the prevalence of chronic pain in the general population is estimated to range from $15.1 \%$ in Canada $^{66}$ to $48.9 \%$ in Sweden. ${ }^{72}$ The majority, if not all, of these studies have identified female gender and age as the risk factors for developing chronic pain. Poor education and low socioeconomic status have been also identified as significant risk factors.

Data from general population studies have shown the prevalence of chronic pain in the elderly can be as high as $55 \%$ after the age of 60 years $^{67}$ and as high as $62 \%$ after the age of 75 years. ${ }^{56}$ The prevalence of chronic pain remains the same in the age group 60-74 and the age group $>75$, however the data for this statement are limited. ${ }^{67}$

Few studies have specifically looked into the elderly, ${ }^{73-80}$ and similar to the epidemiologic studies of the prevalence of chronic pain in the general population, the prevalence of chronic pain in the elderly also varies widely from $15.2 \%$ in Malaysia ${ }^{77}$ to $69.8 \%$ in Germany. ${ }^{79}$ This percentage is even higher (up to $83 \%$ ) among the elderly people living in nursing homes. ${ }^{81,82}$ This is expected, as people in nursing homes are less healthy and not representative of the general population. Also, similar to the general population studies, female gender, obesity and poor economic status are the risk factors for chronic pain in the elderly.

The commonest type of pain in the elderly is back pain $;^{74,76}$ however, not many large studies of prevalence of the specific subtype and the etiology of pain have been conducted in the elderly.

\section{Comorbidity of depression and chronic pain in the elderly}

In some general populations, epidemiologic studies have shown that chronic pain increases the risk for depression between 2.5 and 4.1 times. $^{75,79}$ Similarly, patients suffering from a major depressive disorder are three times more likely to suffer from non-neuropathic pain and six times more likely to suffer from neuropathic pain. ${ }^{61}$ These data contribute to the hypothesis that the common pathogenic factor between chronic pain and depression could be represented by the chronic, subclinical, neuroinflammation.

As both depression and chronic pain are prevalent in the elderly, coexistence of the two entities is not uncommon. ${ }^{83-86}$ Using validated tools for the diagnosis of depression, it has been shown that $13 \%$ of the elderly suffer from both depression and chronic pain. ${ }^{87}$
Pain severity is strongly associated with depression in the elderly, whereas this association is not demonstrated in younger people. ${ }^{81,88}$ Female gender is strongly associated with the comorbidity of the two entities, with women being more likely to suffer from chronic pain if they also suffer from depression. ${ }^{89}$

Only limited data are available about the risk for depression based on the anatomic sites of pain. In one study, it was shown that chronic chest pain was independently associated with depression, while pain in other locations such as neck, back or joint pain was not. ${ }^{90}$ No large studies have been published to date about the subtypes of chronic pain and their relation to depression in the elderly.

\section{Perception of pain and the role of depression}

Pain perception varies significantly among patients and is sensitive to various factors including genetic predisposition ${ }^{91}$ and gender, with female patients experiencing greater clinical pain, suffering greater pain-related distress and showing heightened sensitivity to experimentally induced pain compared with men. ${ }^{92}$ Also, perception of pain is sensitive to various mental processes such as the feelings and beliefs that someone has about pain..$^{93}$ It is, therefore, not exclusively driven by the noxious input. ${ }^{93}$

A cognitive behavioral model has been proposed to explain the role of cognitive appraisal variables in mediating the development of emotional distress following pain of long duration. There is little evidence linking the prevalence of depression in chronic pain patients to life stage, but there are suggestions in the literature that the link between medical illness and depression may be stronger in elderly patients. ${ }^{88}$

Although it was initially suggested that depressed subjects are less likely to perceive an experimental sensory stimulus as being painful compared with nondepressed controls, ${ }^{94}$ subsequent studies showed that painful stimuli are processed differentially, depending on the localization of pain induction in depression. ${ }^{95}$ Klauenberg et $\mathrm{al}^{96}$ showed that in pain-free patients, signs of an enhanced central hyperexcitability are even more pronounced than usually found in chronic pain patients, indicating common mechanisms in depressive disorder and chronic pain in accordance with the assumption of non-pain-associated mechanisms in depressive disorder for central hyperexcitability, for example, by inhibited serotonergic function. Again, the common mechanism could be represented by neuroinflammation.

In a recent meta-analysis of experimental studies, Thompson et $\mathrm{al}^{97}$ concluded that potential effects of depression on pain perception are variable and likely to 
depend upon multiple factors, including the stimulus modality. This conclusion could help explain the discrepancies across clinical and experimental findings; ${ }^{97}$ however, further studies on the links between depression and pain perception area are needed in all age groups, including the elderly.

\section{The role of neuroinflammation}

In the last decades, a dramatic revolution within the scope of neurosciences and underlying immunologic mechanisms has been documented. The concept of central nervous system (CNS) immune privilege had been enormously questioned, as long as an ongoing scientific work managed to illustrate a clear interaction between CNS and the peripheral inflammatory response. ${ }^{98}$ The congenital defensive system of the host, composed of the blood-brain barrier, cellular and molecular components, provides an immediate answer to pathogen-associated molecular patterns, ${ }^{99}$ while the adaptive system produces a delayed, highly specialized response and also creates immunologic memory. Indeed, it begins as a beneficial process; however, an excessive and unresolved reply could have harmful outcome. ${ }^{100}$

In chronic pain, neuroinflammation is often the result of peripheral damage and excessive neuronal activity of primary sensory neurons. ${ }^{13}$ Glia and mast cells are the main coplayers of the somatosensory system, ${ }^{101}$ while their miscommunication promotes impaired neuronal cell functionality. Microglia, in particular, are the main resident macrophage-like cells of the CNS. Their activation is quite a complex process that results in several phenotypes. ${ }^{102}$ Interestingly, during chronic inflammation, microglia may exist in a range of phenotypic states. Specifically, in the aging brain, microglia are mostly present in a "primed" phenotype (Figure 1), ${ }^{103}$ meaning they are primed by previous pathology, or by genetic predisposition, to respond more vigorously to subsequent inflammatory stimulation. ${ }^{104,105}$ Recently, Loggia et al ${ }^{106}$ documented in vivo the predominantly thalamic occurrence of glial activation, as measured by an increase in ${ }^{11} \mathrm{C}-\mathrm{PBR} 28$ binding using positron emission tomography-magnetic resonance imaging, in patients with chronic low back pain.

In addition, the mast cells make an essential contribution to the inflammatory process. Mast cells represent a potentially significant peripheral immune signaling link to the brain. ${ }^{105}$ The increased endoneural number and their progressive hyperreactivity with age play a major role in the determination of the altered functionality of the pain receptors and the pain primary fibers. ${ }^{9}$ Mast cell degranulation is known to activate pain pathways and elicit tactile pain hypersensitivity, possibly by releasing substances that interfere with or sensitize nociceptors. ${ }^{105}$

Moreover, there is evidence that inflammation in the CNS may contribute to pain sensitization and chronification. In regards to neuropathic pain, human studies investigating

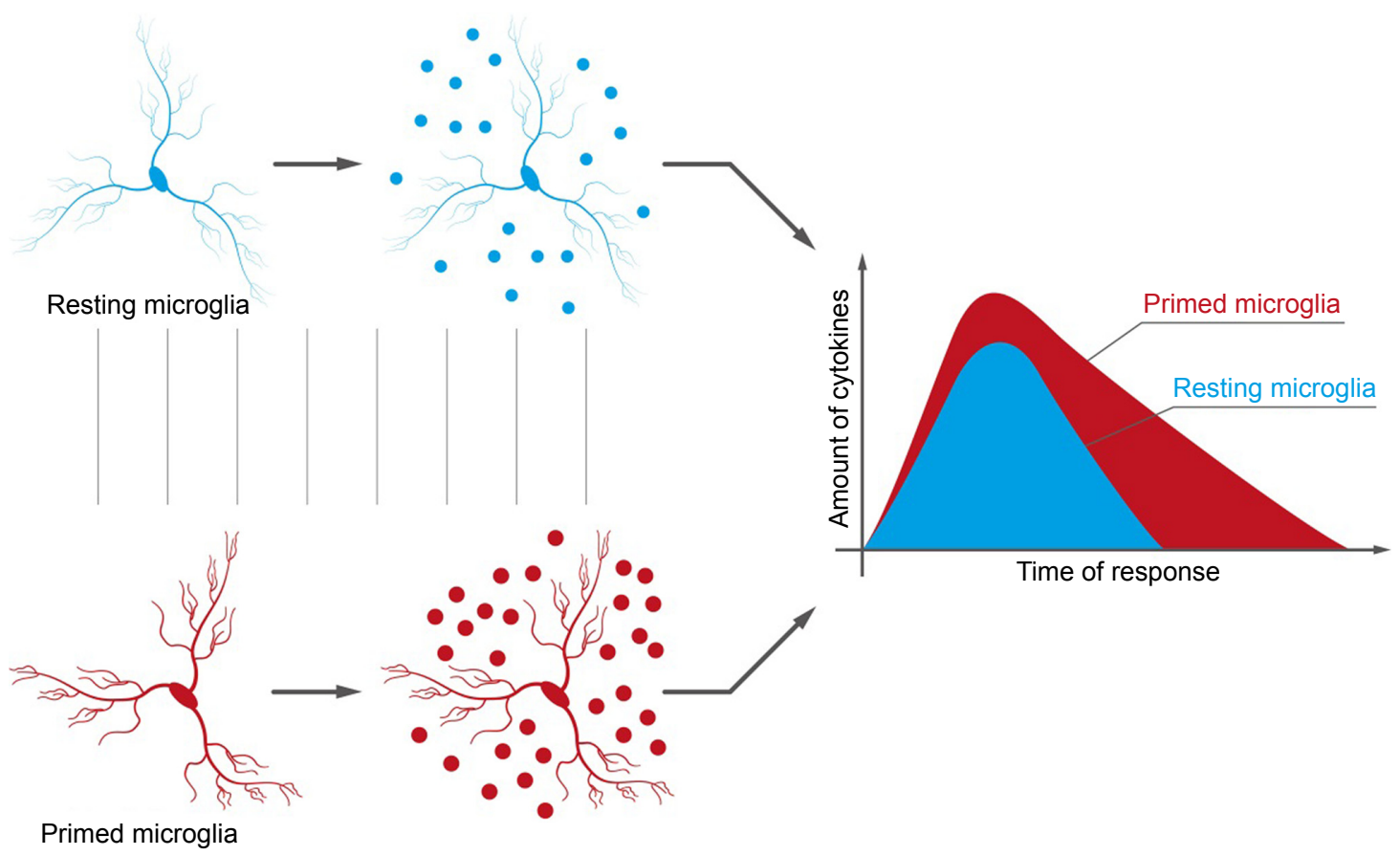

Figure I The differences between normal and "primed" microglia consist of an increased sensibility of the latter to any kind of stimulation. The consequence is an increased production of cytokines.

Note: Copyright, with permission from Pain Nursing Magazine, Fusco M, Paladini A, Skaper SD, Varrassi G. Chronic and neuropathic pain syndrome in the elderly: Pathophysiological basis and perspectives for a rational therapy. Pain Nursing Magazine. 2014;3:94-104. ${ }^{156}$ 
cytokine profiles in the cerebrospinal fluid have indicated that it may be the balance between proinflammatory and anti-inflammatory cytokine profiles. ${ }^{107}$

Similarly, it has been proposed that the inflammatory processes in depression induce alterations of immune regulation in the CNS. ${ }^{108}$ High corticosterone levels and peripheral increased expression of cytokines that are actively transported into the CNS may lead to microglia and astrocyte stimulation, which in turn produce further cytokines through a feedback mechanism. ${ }^{109}$ This activation may then promote the suppression of neurogenesis and neuroplasticity, further enhancing the development of depression-like symptoms, suggesting that a prior inflammation may set the basis for the emergence of depression. ${ }^{110}$

Since chronic pain and depression coexist with such high prevalence, it is rational to hypothesize that common underlying pathogenic mechanisms might exist. ${ }^{107}$

\section{Management}

Managing an elderly patient with comorbid chronic pain and depression is often a challenge. Of course, a patient might receive treatment for each condition separately based on the relevant guidelines; however, there are pharmacologic and some nonpharmacologic approaches worth considering.

\section{Pharmacologic approaches targeting both depression and chronic pain}

Evidence to date indicates that pharmacotherapy focused on both depression and chronic pain in older adults may yield superior outcomes than focusing on only one condition. ${ }^{111-113}$

\section{Selective serotonin reuptake inhibitors}

Although there is no ideal antidepressant in the elderly, in general, selective serotonin reuptake inhibitors (SSRIs) are tolerated better than others. However, SSRIs increase the risk of gastrointestinal and other bleeds (such as hemorrhagic stroke), particularly in the very elderly and those with established risk factors, and therefore should be used with caution. ${ }^{114}$ Only a few trials of SSRIs have been conducted in the management of chronic pain. Fluoxetine was found to relieve low back pain and whiplash-associated cervical pain. ${ }^{114}$ Also, fluoxetine was found to improve the overall quality of chronic pain; however, this observation depended more on an improvement in depressive symptoms of the patients. ${ }^{115}$ Similarly, Aragona et al $^{116}$ showed that citalopram may have a moderate analgesic effect in patients with pain, and that this analgesic activity appeared to be not correlated to changes in depressive scores. Shimodozono et $\mathrm{al}^{117}$ showed that fluvoxamine is useful for the control of central post-stroke pain, regardless of depression, when used relatively early after stroke. The therapeutic effect of fluvoxamine on the neuropathic component of pain was also observed by Ciaramella et al. ${ }^{115}$ Finally, a placebo-controlled trial of sertraline showed a significant improvement in men with chronic pelvic pain syndrome. ${ }^{118}$

Although there are some reports supporting the effectiveness of SSRIs in the management of pain, they are few in number. Replication of larger randomized controlled trials is needed to prove the efficacy of SSRIs in the treatment of pain in the general population and in the elderly.

\section{Selective norepinephrine reuptake inhibitors}

Duloxetine is a serotonin norepinephrine reuptake inhibitor which has been shown to be effective both as an antidepressant and for chronic pain in the elderly. ${ }^{119}$ The analgesic effect includes both its effect on neuropathic pain, such as pain secondary to diabetic neuropathy, ${ }^{120}$ and in the management of chronic musculoskeletal pain. ${ }^{121}$

Venlafaxine is a safe and well-tolerated serotonin norepinephrine reuptake inhibitor that can be used for the symptomatic treatment of neuropathic pain. ${ }^{122}$ Venlafaxine exerts its effects on the modulation of spinal nociceptive transmission, which may reflect changes in balance between descending inhibition and descending facilitation. ${ }^{123}$ Experimental rat studies showed that when venlafaxine is administered as an adjuvant to tramadol, additive action in reducing hyperalgesia and allodynia has been observed. ${ }^{124}$ However, a study conducted by Cegielska-Perun et $\mathrm{al}^{125}$ has shown that whereas acute coadministration of venlafaxine increases the analgesic activity of morphine, chronic treatment with venlafaxine attenuates opioid efficacy.

\section{Tricyclic antidepressants}

Amitriptyline, clomipramine and nortriptyline are the most commonly used tricyclic antidepressants. Tricyclic antidepressants can decrease the pain perception, ${ }^{126}$ and are used in various forms of pain including cancer pain, ${ }^{126}$ orofacial pain, ${ }^{127,128}$ fibromyalgia, ${ }^{129}$ central neuropathic pain ${ }^{130}$ and peripheral neuropathic pain. ${ }^{131}$ In the treatment of peripheral neuropathic pain, amitriptyline and nortriptyline have equivalent overall adverse effects and discontinuation rates, and both can be equally considered either as monotherapy or as part of combination therapy. ${ }^{131}$ For the treatment of central pain, clomipramine is significantly more effective compared to nortriptyline. ${ }^{130}$ 
Noradrenergic and specific serotonergic antidepressants

Mirtazapine is the most commonly used antidepressant in this category. It has been shown that mirtazapine can increase the pain tolerance in healthy people. ${ }^{132}$ Yet, limited studies of the effectiveness of mirtazapine in pain are available. In an open-label crossover trial, it was shown that mirtazapine might relieve pain in cancer patients. ${ }^{133}$

\section{Norepinephrine-dopamine reuptake inhibitors}

Buproprion is primarily used as an antidepressant and smoking cessation aid. No human studies of its analgesic properties have been conducted; however, a study in mice showed that it has a significant antiallodynic effects. ${ }^{134}$

\section{Serotonin antagonist and reuptake inhibitors}

Trazodone is the most commonly used antidepressant in this category. Trazodone is equally efficacious to amitriptyline in cancer pain, ${ }^{135}$ and it is efficacious in fibromyalgia. ${ }^{136}$ However, no therapeutic effect was shown in chronic low back pain ${ }^{137}$ and orofacial pain. ${ }^{138}$

\section{Nonpharmacologic approaches targeting both depression and chronic pain \\ Psychotherapeutic approaches}

A vicious cycle of chronic pain and depression (Figure 2) involved a constant interaction between cognitions (thoughts), behaviors, somatic reactions (ie, pain) and emotions. As pain has cognitive and emotional components, a psychotherapeutic approach to its management can be justified. Reappraisal of

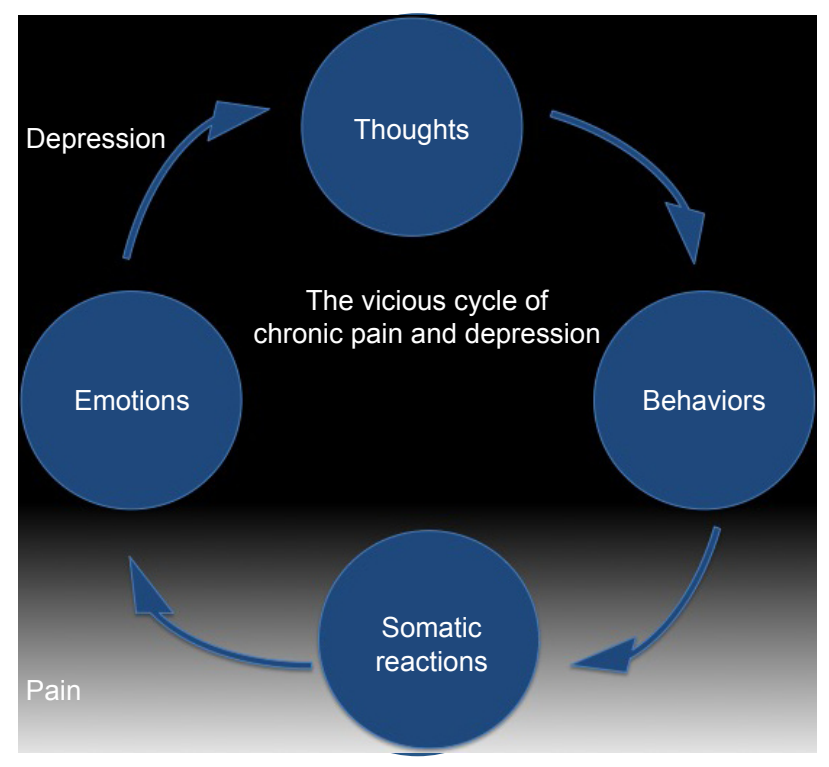

Figure 2 Relationship between chronic pain and depression, and the vicious cycle existing between the two pathologies. the negative experiences of pain can lead to reduction of pain perception. Recent studies have observed that brain activation is more related to the intensity of expected pain than to the real intensity of the noxious stimuli. In other words, positive expectations reduce the severity of pain perception. ${ }^{139}$ Reformulating the significance of an event and reinterpreting its meaning is the principal aim of any psychotherapeutic intervention. A number of psychotherapeutic and adjunctive techniques can, therefore, be used to address the psychological and social features associated with and contributing to pain. ${ }^{11,139}$

Cognitive behavioral therapy (CBT) has demonstrated clinical benefit for both depression and chronic pain. ${ }^{140-143}$ CBT for chronic pain and major depressive disorder utilizes similar techniques such as learning to pace activities, reinforcement of adaptive responses, reframing cognitive responses, learning coping and problem-solving skills, and relaxation techniques. ${ }^{144,145}$

Computerized CBT programs are also becoming increasingly available ${ }^{146}$ and should be considered for elderly patients who are computer savvy and/or have limited access to mental health care. A recent meta-analysis examined the effect of computerized CBT on chronic pain and concluded that web-based interventions for chronic pain yield small reduction in pain in the intervention group compared with the waiting-list control groups. ${ }^{147}$

Acceptance and commitment therapy is another form of psychotherapy that can be used in depression and chronic pain. Several studies have shown that greater acceptance of pain is associated with reports of lower pain intensity, less pain-related anxiety and avoidance, less depression, less physical and psychosocial disability, and greater physical and social ability. ${ }^{148,149}$

Brief psychodynamic approach is usually combined with psychopharmacologic treatments for the treatment of elderly patients with oncologic pain. It has demonstrated a significant reduction in pain perception and depression, when compared to the pharmacologic treatment alone. ${ }^{150}$

\section{Acupuncture}

Accumulating evidence suggests that acupuncture can be very effective in the treatment of chronic pain and depression, even in the primary care. ${ }^{151}$ Usually, acupuncture is used as an adjuvant approach, and it has been shown that it is effective in both reducing depression and pain, compared to counseling or usual care alone. ${ }^{152}$

\section{Other nonpharmacologic approaches}

Good quality studies on other nonpharmacologic approaches are lacking; however, some reports suggest that hypnotherapy, ${ }^{153}$ 
physical exercise ${ }^{154}$ and relaxation techniques ${ }^{155}$ might be helpful in targeting depression and pain.

\section{Conclusion}

This review indicates the following key points:

1. Both chronic pain and depression are prevalent in old age and they have a bidirectional relationship. Both depression and pain might be risk factors for each other.

2. Robust epidemiologic data focusing on the prevalence of chronic pain subtypes and comorbid depression are lacking. Epidemiologic studies from different countries are not only of help to tailor management strategies, but also useful in understanding other underlying risk factors, which may account for the wide range of prevalence of chronic pain and depression in the elderly that has been reported so far.

3. There is increasing evidence of the role of neuroinflammation for the development of both chronic pain and depression.

4. Pharmacologic studies of antidepressant agents targeting chronic pain and depression simultaneously are lacking, especially in the elderly populations.

5. The role of nonpharmacologic approaches in the management of pain and depression is increasingly drawing attention. These approaches not only include psychotherapeutic interventions, but also acupuncture, hypnotherapy, physical exercise and relaxation techniques. However, better quality studies would be necessary.

The patient should always be part of the decision making in terms of management. With numerous pharmacologic agents and nonpharmacologic approaches in their armamentarium, the pain physicians can tailor the treatment based on each patient's needs.

\section{Disclosure}

The authors report no conflicts of interest in this work.

\section{References}

1. Wallace DC. The inevitability of growing old. JChronic Dis. 1967;20(7): 475-486.

2. Niccoli T, Partridge L. Ageing as a risk factor for disease. Curr Biol. 2012;22(17):R741-R752.

3. Maercker A, Forstmeier S, Enzler A, et al. Adjustment disorders, posttraumatic stress disorder, and depressive disorders in old age: findings from a community survey. Compr Psychiatry. 2008;49(2):113-120.

4. Diegelmann M, Schilling OK, Wahl HW. Feeling blue at the end of life: trajectories of depressive symptoms from a distance-to-death perspective. Psychol Aging. 2016;31(7):672-686.

5. Anderson DN. Treating depression in old age: the reasons to be positive. Age Ageing. 2001;30(1):13-17.
6. Smith OR, Kupper N, Schiffer AA, Denollet J. Somatic depression predicts mortality in chronic heart failure: can this be explained by covarying symptoms of fatigue? Psychosom Med. 2012;74(5):459-463.

7. Sykioti $P, Z$ is $P$, Vadalouca A, et al. Validation of the Greek Version of the DN4 diagnostic questionnaire for neuropathic pain. Pain Pract. 2015;15(7):627-632.

8. Classification of chronic pain. Descriptions of chronic pain syndromes and definitions of pain terms. Prepared by the International Association for the Study of Pain, Subcommittee on Taxonomy. Pain Suppl. 1986;3:S1-S226.

9. Varrassi G, Fusco M, Coaccioli S, Paladini A. Chronic pain and neurodegenerative processes in elderly people. Pain Pract. 2015;15(1):1-3.

10. Ferrari AJ, Charlson FJ, Norman RE, et al. Burden of depressive disorders by country, sex, age, and year: findings from the global burden of disease study 2010. PLoS Med. 2013;10(11):e1001547.

11. World Health Organization. Media Centre. Depression. Fact Sheet Reviewed April; 2016 [Internet]. Available from: http://www.who.int/ mediacentre/factsheets/fs369/en/. Accessed February 1, 2017.

12. Baquero M, Martín N. Depressive symptoms in neurodegenerative diseases. World J Clin Cases. 2015;3(8):682-693.

13. Ji RR, Xu ZZ, Gao YJ. Emerging targets in neuroinflammation-driven chronic pain. Nat Rev Drug Discov. 2014;13(7):533-548.

14. Petersen RC, Caracciolo B, Brayne C, Gauthier S, Jelic V, Fratiglioni L. Mild cognitive impairment: a concept in evolution. J Intern Med. 2014; 275(3):214-228.

15. Palmer K, Berger AK, Monastero R, Winblad B, Bäckman L, Fratiglioni L. Predictors of progression from mild cognitive impairment to Alzheimer disease. Neurology. 2007;68(19):1596-1602.

16. Achterberg WP, Pieper MJ, van Dalen-Kok AH, et al. Pain management in patients with dementia. Clin Interv Aging. 2013;8:1471-1482.

17. Treede RD, Rief W, Barke A, et al. A classification of chronic pain for ICD-11. Pain. 2015;156(6):1003-1007.

18. Treede RD, Jensen TS, Campbell JN, et al. Neuropathic pain: redefinition and a grading system for clinical and research purposes. Neurology. 2008;70(18):1630-1635.

19. Baron R, Binder A. How neuropathic is sciatica? The mixed pain concept. Orthopade. 2004;33(5):568-575. German.

20. Vadalouca A, Raptis E, Moka E, Zis P, Sykioti P, Siafaka I. Pharmacological treatment of neuropathic cancer pain: a comprehensive review of the current literature. Pain Pract. 2012;12(3):219-251.

21. Hanewinckel R, Drenthen J, van Oijen M, Hofman A, van Doorn PA, Ikram MA. Prevalence of polyneuropathy in the general middle-aged and elderly population. Neurology. 2016;87(18):1892-1898.

22. Schreiber AK, Nones CF, Reis RC, Chichorro JG, Cunha JM. Diabetic neuropathic pain: physiopathology and treatment. World J Diabetes. 2015;6(3):432-444.

23. Chopra K, Tiwari V. Alcoholic neuropathy: possible mechanisms and future treatment possibilities. Br J Clin Pharmacol. 2012;73(3): 348-362.

24. Hadjivassiliou M, Grünewald RA, Kandler RH, et al. Neuropathy associated with gluten sensitivity. J Neurol Neurosurg Psychiatry. 2006; 77(11):1262-1266.

25. Zis P, Zis V, Xirou S, Kemanetzoglou E, Zambelis T, Karandreas N. Rapid screening for carpal tunnel syndrome: a novel method and comparison with established others. J Clin Neurophysiol. 2015;32(4):375-379.

26. Zis P, Sarrigiannis PG, Rao DG, Hewamadduma C, Hadjivassiliou M. Chronic idiopathic axonal polyneuropathy: a systematic review. J Neurol. 2016;263(10):1903-1910.

27. Zis P, Rizos A, Martinez-Martin P, et al. Non-motor symptoms profile and burden in drug naïve versus long-term Parkinson's disease patients. J Parkinsons Dis. 2014;4(3):541-547.

28. Zis P, Martinez-Martin P, Sauerbier A, et al. Non-motor symptoms burden in treated and untreated early Parkinson's disease patients: argument for non-motor subtypes. Eur J Neurol. 2015;22(8):1145-1150.

29. Zis P, Sokolov E, Chaudhuri KR. An overview of pain in Parkinson's. In: Battaglia AA, editor. An Introduction to Pain and Its Relation to Nervous System Disorders. UK: John Wiley \& Sons. 2016:387. 
30. Zis P, Erro R, Walton CC, Sauerbier A, Chaudhuri KR. The range and nature of non-motor symptoms in drug-naive Parkinson's disease patients: a state-of-the-art systematic review. Parkinson's Disease. 2015;1:15013.

31. Gullo L, Sipahi HM, Pezzilli R. Pancreatitis in the elderly. J Clin Gastroenterol. 1994;19(1):64-68.

32. Hohenwalter EJ. Chronic mesenteric ischemia: diagnosis and treatment Semin Intervent Radiol. 2009;26(4):345-351.

33. Miller G, Boman J, Shrier I, Gordon PH. Natural history of patients with adhesive small bowel obstruction. Br J Surg. 2000;87(9): 1240-1247.

34. Stavropoulou E, Argyra E, Zis P, Vadalouca A, Siafaka I. The effect of intravenous lidocaine on trigeminal neuralgia: a randomized double blind placebo controlled trial. ISRN Pain. 2014;2014:853826.

35. Schiffman E, Ohrbach R, Truelove E, et al; International RDC/TMD Consortium Network, International association for Dental Research; Orofacial Pain Special Interest Group, International Association for the Study of Pain. Diagnostic Criteria for Temporomandibular Disorders (DC/TMD) for clinical and research applications: recommendations of the International RDC/TMD consortium network* and orofacial pain special interest group. J Oral Facial Pain Headache. 2014;28(1):6-27.

36. Zis P, Bernali N, Argira E, Siafaka I, Vadalouka A. Effectiveness and impact of capsaicin $8 \%$ patch on quality of life in patients with lumbosacral pain: an open-label study. Pain Physician. 2016;19(7): E1049-E1053.

37. Zis P, Brozou V, Stavropoulou E, et al. Validation of the Greek Version of the fibromyalgia rapid screening tool. Pain Pract. Epub 2016 Dec 20.

38. United Nations. World population ageing 2015. Population Division, Department of Economic and Social Affairs, New York, NY: United Nations; 2015.

39. Ma X, Xiang YT, Li SR, et al. Prevalence and sociodemographic correlates of depression in an elderly population living with family members in Beijing, China. Psychol Med. 2008;38(12):1723-1730.

40. Kim JI, Choe MA, Chae YR. Prevalence and predictors of geriatric depression in community-dwelling elderly. Asian Nurs Res (Korean Soc Nurs Sci). 2009;3(3):121-129.

41. Wong SY, Mercer SW, Woo J, Leung J. The influence of multi-morbidity and self-reported socio-economic standing on the prevalence of depression in an elderly Hong Kong population. BMC Public Health. 2008;8:119.

42. Yohannes AM, Baldwin RC, Connolly MJ. Prevalence of depression and anxiety symptoms in elderly patients admitted in post-acute intermediate care. Int J Geriatr Psychiatry. 2008;23(11):1141-1147.

43. Helvik AS, Skancke RH, Selbaek G. Screening for depression in elderly medical inpatients from rural area of Norway: prevalence and associated factors. Int J Geriatr Psychiatry. 2010;25(2):150-159.

44. Imran A, Azidah AK, Asrenee AR, Rosediani M. Prevalence of depression and its associated factors among elderly patients in outpatient clinic of Universiti Sains Malaysia Hospital. Med J Malaysia. 2009;64(2):134-139.

45. Levin CA, Wei W, Akincigil A, Lucas JA, Bilder S, Crystal S. Prevalence and treatment of diagnosed depression among elderly nursing home residents in Ohio. J Am Med Dir Assoc. 2007;8(9): 585-594.

46. Michopoulos I, Douzenis A, Gournellis R, et al. Major depression in elderly medical inpatients in Greece, prevalence and identification. Aging Clin Exp Res. 2010;22(2):148-151.

47. Baiyewu O, Smith-Gamble V, Lane KA, et al. Prevalence estimates of depression in elderly community-dwelling African Americans in Indianapolis and Yoruba in Ibadan, Nigeria. Int Psychogeriatr. 2007;19(4):679-689.

48. Rajkumar AP, Thangadurai P, Senthilkumar P, Gayathri K, Prince M, Jacob KS. Nature, prevalence and factors associated with depression among the elderly in a rural south Indian community. Int Psychogeriatr. 2009;21(2):372-378.
49. Volkert J, Schulz H, Härter M, Wlodarczyk O, Andreas S. The prevalence of mental disorders in older people in Western countries - a metaanalysis. Ageing Res Rev. 2013;12(1):339-353.

50. Solhaug HI, Romuld EB, Romild U, Stordal E. Increased prevalence of depression in cohorts of the elderly: an 11-year follow-up in the general population - the HUNT study. Int Psychogeriatr. 2012;24(1): $151-158$.

51. Ganatra HA, Zafar SN, Qidwai W, Rozi S. Prevalence and predictors of depression among an elderly population of Pakistan. Aging Ment Health. 2008;12(3):349-356.

52. Hornsten C, Molander L, Gustafson Y. The prevalence of stroke and the association between stroke and depression among a very old population. Arch Gerontol Geriatr. 2012;55(3):555-559.

53. Schopflocher D, Taenzer P, Jovey R. The prevalence of chronic pain in Canada. Pain Res Manag. 2011;16(6):445-450.

54. Jackson T, Thomas S, Stabile V, Han X, Shotwell M, McQueen K. Prevalence of chronic pain in low-income and middle-income countries: a systematic review and meta-analysis. Lancet. 2015; 385 (Suppl 2):S10.

55. Leão Ferreira KA, Bastos TR, Andrade DC, et al. Prevalence of chronic pain in a metropolitan area of a developing country: a population-based study. Arq Neuropsiquiatr. 2016;74(12):990-998.

56. Cheung CW, Choi SW, Wong SS, Lee Y, Irwin MG. Changes in prevalence, outcomes, and help-seeking behavior of chronic pain in an aging population over the last decade. Pain Pract. Epub 2016 Oct 13.

57. Fayaz A, Croft P, Langford RM, Donaldson LJ, Jones GT. Prevalence of chronic pain in the UK: a systematic review and meta-analysis of population studies. BMJ Open. 2016;6(6):e010364.

58. Dueñas M, Salazar A, Ojeda B, et al. A nationwide study of chronic pain prevalence in the general spanish population: identifying clinical subgroups through cluster analysis. Pain Med. 2015;16(4):811-822.

59. Cabral DM, Bracher ES, Depintor JD, Eluf-Neto J. Chronic pain prevalence and associated factors in a segment of the population of São Paulo City. J Pain. 2014;15(11):1081-1091.

60. Häuser W, Wolfe F, Henningsen P, Schmutzer G, Brähler E, Hinz A. Untying chronic pain: prevalence and societal burden of chronic pain stages in the general population - a cross-sectional survey. BMC Public Health. 2014;14:352.

61. Ohayon MM, Stingl JC. Prevalence and comorbidity of chronic pain in the German general population. J Psychiatr Res. 2012;46(4):444-450.

62. Jackson T, Chen H, Iezzi T, Yee M, Chen F. Prevalence and correlates of chronic pain in a random population study of adults in Chongqing, China. Clin J Pain. 2014;30(4):346-352.

63. Harifi G, Amine M, Ait Ouazar M, et al. Prevalence of chronic pain with neuropathic characteristics in the Moroccan general population: a national survey. Pain Med. 2013;14(2):287-292.

64. Azevedo LF, Costa-Pereira A, Mendonça L, Dias CC, Castro-Lopes JM. Epidemiology of chronic pain: a population-based nationwide study on its prevalence, characteristics and associated disability in Portugal J Pain. 2012;13(8):773-783.

65. Reitsma M, Tranmer JE, Buchanan DM, VanDenKerkhof EG. The epidemiology of chronic pain in Canadian men and women between 1994 and 2007: longitudinal results of the National Population Health Survey. Pain Res Manag. 2012;17(3):166-172.

66. Reitsma ML, Tranmer JE, Buchanan DM, Vandenkerkhof EG. The prevalence of chronic pain and pain-related interference in the Canadian population from 1994 to 2008. Chronic Dis Inj Can. 2011; 31(4):157-164.

67. Jakobsson U. The epidemiology of chronic pain in a general population: results of a survey in southern Sweden. Scand J Rheumatol. 2010;39(5):421-429.

68. Sá K, Baptista AF, Matos MA, Lessa I. Prevalence of chronic pain and associated factors in the population of Salvador, Bahia. Rev Saude Publica. 2009;43(4):622-630. English, Portuguese.

69. Bouhassira D, Lantéri-Minet M, Attal N, Laurent B, Touboul C. Prevalence of chronic pain with neuropathic characteristics in the general population. Pain. 2008;136(3):380-387. 
70. Torrance N, Smith BH, Bennett MI, Lee AJ. The epidemiology of chronic pain of predominantly neuropathic origin. Results from a general population survey. J Pain. 2006;7(4):281-289.

71. Rustøen T, Wahl AK, Hanestad BR, Lerdal A, Paul S, Miaskowski C. Prevalence and characteristics of chronic pain in the general Norwegian population. Eur J Pain. 2004;8(6):555-565.

72. Gerdle B, Björk J, Henriksson C, Bengtsson A. Prevalence of current and chronic pain and their influences upon work and healthcare-seeking: a population study. J Rheumatol. 2004;31(7):1399-1406.

73. dos Santos FA, de Souza JB, Antes DL, d'Orsi E. Prevalence of chronic pain and its association with the sociodemographic situation and physical activity in leisure of elderly in Florianópolis, Santa Catarina: population-based study. Rev Bras Epidemiol. 2015;18(1):234-247. English, Portuguese.

74. Dellaroza MS, Pimenta CA, Matsuo T. Prevalence and characterization of chronic pain among the elderly living in the community. Cad Saude Publica. 2007;23(5):1151-1160.

75. McCarthy LH, Bigal ME, Katz M, Derby C, Lipton RB. Chronic pain and obesity in elderly people: results from the Einstein aging study. J Am Geriatr Soc. 2009;57(1):115-119.

76. Dellaroza MS, Pimenta CA, Duarte YA, Lebrão ML. Chronic pain among elderly residents in São Paulo, Brazil: prevalence, characteristics, and association with functional capacity and mobility (SABE Study). Cad Saude Publica. 2013;29(2):325-334. Portuguese.

77. Mohamed Zaki LR, Hairi NN. Chronic pain and pattern of health care utilization among Malaysian elderly population: National Health and Morbidity Survey III (NHMS III, 2006). Maturitas. 2014;79(4):435-441.

78. Barbosa MH, Bolina AF, Tavares JL, Cordeiro AL, Luiz RB, de Oliveira KF. Sociodemographic and health factors associated with chronic pain in institutionalized elderly. Rev Lat Am Enfermagem. 2014; 22(6):1009-1016. English, Portuguese, Spanish.

79. Bauer H, Emeny RT, Baumert J, Ladwig KH. Resilience moderates the association between chronic pain and depressive symptoms in the elderly. Eur J Pain. 2016;20(8):1253-1265.

80. Larsson C, Hansson EE, Sundquist K, Jakobsson U. Chronic pain in older adults: prevalence, incidence, and risk factors. Scand J Rheumatol. 2016:1-9.

81. Roy R, Thomas M. A survey of chronic pain in an elderly population. Can Fam Physician. 1986;32:513-516.

82. Zanocchi M, Maero B, Nicola E, et al. Chronic pain in a sample of nursing home residents: prevalence, characteristics, influence on quality of life (QoL). Arch Gerontol Geriatr. 2008;47(1):121-128.

83. Roy R. A psychosocial perspective on chronic pain and depression in the elderly. Soc Work Health Care. 1986;12(2):27-36.

84. Herr KA, Mobily PR. Chronic pain and depression. J Psychosoc Nurs Ment Health Serv. 1992;30(9):7-12.

85. Klinger L, Spaulding SJ, Polatajko HJ, MacKinnon JR, Miller L. Chronic pain in the elderly: occupational adaptation as a means of coping with osteoarthritis of the hip and/or knee. Clin J Pain. 1999;15(4):275-283.

86. Tsai PF, Tak S, Moore C, Palencia I. Testing a theory of chronic pain. J Adv Nurs. 2003;43(2):158-169.

87. Mossey JM, Gallagher RM. The longitudinal occurrence and impact of comorbid chronic pain and chronic depression over two years in continuing care retirement community residents. Pain Med. 2004;5(4):335-348.

88. Turk DC, Okifuji A, Scharff L. Chronic pain and depression: role of perceived impact and perceived control in different age cohorts. Pain. 1995;61(1):93-101.

89. Scherer M, Hansen H, Gensichen J, et al. Association between multimorbidity patterns and chronic pain in elderly primary care patients: a cross-sectional observational study. BMC Fam Pract. 2016;17:68.

90. Oladeji BD, Makanjuola VA, Esan OB, Gureje O. Chronic pain conditions and depression in the Ibadan Study of Ageing. Int Psychogeriatr. 2011;23(6):923-929.

91. Diatchenko L, Nackley AG, Tchivileva IE, Shabalina SA, Maixner W. Genetic architecture of human pain perception. Trends Genet. 2007; 23(12):605-613.

92. Paller CJ, Campbell CM, Edwards RR, Dobs AS. Sex-based differences in pain perception and treatment. Pain Med. 2009;10(2):289-299.
93. Wiech K, Ploner M, Tracey I. Neurocognitive aspects of pain perception. Trends Cogn Sci. 2008;12(8):306-313.

94. Dickens C, McGowan L, Dale S. Impact of depression on experimental pain perception: a systematic review of the literature with meta-analysis. Psychosom Med. 2003;65(3):369-375.

95. Bär KJ, Brehm S, Boettger MK, Boettger S, Wagner G, Sauer H. Pain perception in major depression depends on pain modality. Pain. 2005; 117(1-2):97-103.

96. Klauenberg S, Maier C, Assion HJ, et al. Depression and changed pain perception: hints for a central disinhibition mechanism. Pain. 2008; 140(2):332-343

97. Thompson T, Correll CU, Gallop K, Vancampfort D, Stubbs B. Is pain perception altered in people with depression? A systematic review and meta-analysis of experimental pain research. J Pain. 2016;17(12): $1257-1272$.

98. Carson MJ, Doose JM, Melchior B, Schmid CD, Ploix CC. CNS immune privilege: hiding in plain sight. Immunol Rev. 2006;213: 48-65.

99. Lyman M, Lloyd DG, Ji X, Vizcaychipi MP, Ma D. Neuroinflammation: the role and consequences. Neurosci Res. 2014;79:1-12.

100. Rogers J, Mastroeni D, Leonard B, Joyce J, Grover A. Neuroinflammation in Alzheimer's disease and Parkinson's disease: are microglia pathogenic in either disorder? Int Rev Neurobiol. 2007;82: 235-246.

101. Paladini A, Fusco M, Coaccioli S, Skaper SD, Varrassi G. Chronic pain in the elderly: the case for new therapeutic strategies. Pain Physician. 2015;18(5):E863-E876.

102. Heneka MT, Carson MJ, El Khoury J, et al. Neuroinflammation in Alzheimer's disease. Lancet Neurol. 2015;14(4):388-405.

103. Paladini A, Marinangeli F, Coaccioli S, Fusco M, Piroli A, Giustino V. New perspectives in chronic and neuropathic pain in older population. SOJ Anesthesiol Pain Manag. 2015;2(3):1-3.

104. Cunningham C. Microglia and neurodegeneration: the role of systemic inflammation. Glia. 2013;61(1):71-90.

105. Skaper SD, Facci L, Giusti P. Mast cells, glia and neuroinflammation: partners in crime? Immunology. 2014;141(3):314-327.

106. Loggia ML, Chonde DB, Akeju O, et al. Evidence for brain glial activation in chronic pain patients. Brain. 2015;138(Pt 3):604-615.

107. Walker AK, Kavelaars A, Heijnen CJ, Dantzer R. Neuroinflammation and comorbidity of pain and depression. Pharmacol Rev. 2013;66(1):80-101.

108. Hong H, Kim BS, Im HI. Pathophysiological role of neuroinflammation in neurodegenerative diseases and psychiatric disorders. Int Neurourol J. 2016;20(Suppl 1):S2-S7.

109. Réus GZ, Fries GR, Stertz L, et al. The role of inflammation and microglial activation in the pathophysiology of psychiatric disorders. Neuroscience. 2015;300:141-154.

110. Brites D, Fernandes A. Neuroinflammation and depression: microglia activation, extracellular microvesicles and microRNA Dysregulation. Front Cell Neurosci. 2015;9:476.

111. Carley JA, Karp JF, Gentili A, et al. Deconstructing chronic low back pain in the older adult: step by step evidence and expert-based recommendations for evaluation and treatment: part IV: depression. Pain Med. 2015;16(11):2098-2108.

112. Barry LC, Guo Z, Kerns RD, Duong BD, Reid MC. Functional selfefficacy and pain-related disability among older veterans with chronic pain in a primary care setting. Pain. 2003;104(1-2):131-137.

113. Rowe JW, Kahn RL. Successful aging. Aging Clin Exp Res. 1998; 10(2):142-144.

114. Schreiber S, Vinokur S, Shavelzon V, Pick CG, Zahavi E, Shir Y. A randomized trial of fluoxetine versus amitriptyline in musculoskeletal pain. Isr J Psychiatry Relat Sci. 2001;38(2):88-94.

115. Ciaramella A, Grosso S, Poli P. Fluoxetine versus fluvoxamine for treatment of chronic pain. Minerva Anestesiol. 2000;66(1-2):55-61. Italian.

116. Aragona M, Bancheri L, Perinelli D. Randomized double-blind comparison of serotonergic (Citalopram) versus noradrenergic (Reboxetine) reuptake inhibitors in outpatients with somatoform, DSM-IV-TR pain disorder. Eur J Pain. 2005;9(1):33-38. 
117. Shimodozono M, Kawahira K, Kamishita T, Ogata A, Tohgo S, Tanaka N Reduction of central poststroke pain with the selective serotonin reuptake inhibitor fluvoxamine. Int J Neurosci. 2002;112(10):1173-1181.

118. Lee RA, West RM, Wilson JD. The response to sertraline in men with chronic pelvic pain syndrome. Sex Transm Infect. 2005;81(2): 147-149.

119. Raskin J, Wiltse CG, Siegal A, et al. Efficacy of duloxetine on cognition, depression, and pain in elderly patients with major depressive disorder: an 8-week, double-blind, placebo-controlled trial. Am J Psychiatry. 2007;164(6):900-909.

120. Hossain SM, Hussain SM, Ekram AR. Duloxetine in painful diabetic neuropathy: a systematic review. Clin J Pain. 2016;32(11):1005-1010.

121. Smith HS, Smith EJ, Smith BR. Duloxetine in the management of chronic musculoskeletal pain. Ther Clin Risk Manag. 2012;8: 267-277.

122. Aiyer R, Barkin RL, Bhatia A. Treatment of neuropathic pain with venlafaxine: a systematic review. Pain Med. Epub 2016 Nov 11.

123. Lelic D, Fischer IW, Olesen AE, et al. Venlafaxine and oxycodone effects on human spinal and supraspinal pain processing: a randomized cross-over trial. Eur J Neurosci. 2016;44(11):2966-2974.

124. Wrzosek A, Obara I, Wordliczek J, Przewlocka B. Efficacy of tramadol in combination with doxepin or venlafaxine in inhibition of nociceptive process in the rat model of neuropathic pain: an isobolographic analysis. J Physiol Pharmacol. 2009;60(4):71-78.

125. Cegielska-Perun K, Bujalska-Zadrożny M, Makulska-Nowak HE. Modification of morphine analgesia by venlafaxine in diabetic neuropathic pain model. Pharmacol Rep. 2012;64(5): 1267-1275.

126. Magni G, Conlon P, Arsie D. Tricyclic antidepressants in the treatment of cancer pain: a review. Pharmacopsychiatry. 1987;20(4): $160-164$.

127. Kreisberg MK. Tricyclic antidepressants: analgesic effect and indications in orofacial pain. J Craniomandib Disord. 1988;2(4): 171-177.

128. Brown RS, Bottomley WK. Utilization and mechanism of action of tricyclic antidepressants in the treatment of chronic facial pain: a review of the literature. Anesth Prog. 1990;37(5):223-229.

129. Godfrey RG. A guide to the understanding and use of tricyclic antidepressants in the overall management of fibromyalgia and other chronic pain syndromes. Arch Intern Med. 1996;156(10):1047-1052.

130. Panerai AE, Monza G, Movilia P, Bianchi M, Francucci BM, Tiengo M. A randomized, within-patient, cross-over, placebo-controlled trial on the efficacy and tolerability of the tricyclic antidepressants chlorimipramine and nortriptyline in central pain. Acta Neurol Scand. 1990;82(1):34-38.

131. Liu WQ, Kanungo A, Toth C. Equivalency of tricyclic antidepressants in open-label neuropathic pain study. Acta Neurol Scand. 2014;129(2):132-141.

132. Arnold P, Vuadens P, Kuntzer T, Gobelet C, Deriaz O. Mirtazapine decreases the pain feeling in healthy participants. Clin J Pain. 2008; 24(2):116-119

133. Theobald DE, Kirsh KL, Holtsclaw E, Donaghy K, Passik SD. An open-label, crossover trial of mirtazapine (15 and $30 \mathrm{mg}$ ) in cancer patients with pain and other distressing symptoms. J Pain Symptom Manage. 2002;23(5):442-447.

134. Jesse CR, Wilhelm EA, Nogueira CW. Depression-like behavior and mechanical allodynia are reduced by bis selenide treatment in mice with chronic constriction injury: a comparison with fluoxetine, amitriptyline, and bupropion. Psychopharmacology (Berl). 2010; 212(4):513-522.

135. Ventafridda V, Bonezzi C, Caraceni A, et al. Antidepressants for cancer pain and other painful syndromes with deafferentation component: comparison of amitriptyline and trazodone. Ital J Neurol Sci. 1987;8(6):579-587.

136. Calandre EP, Morillas-Arques P, Molina-Barea R, Rodriguez-Lopez CM, Rico-Villademoros F. Trazodone plus pregabalin combination in the treatment of fibromyalgia: a two-phase, 24-week, open-label uncontrolled study. BMC Musculoskelet Disord. 2011;12:95.
137. Goodkin K, Gullion CM, Agras WS. A randomized, double-blind, placebo-controlled trial of trazodone hydrochloride in chronic low back pain syndrome. J Clin Psychopharmacol. 1990;10(4): 269-278

138. Tammiala-Salonen T, Forssell H. Trazodone in burning mouth pain: a placebo-controlled, double-blind study. J Orofac Pain. 1999;13(2): 83-88.

139. Torta RG, Munari J. Symptom cluster: depression and pain. Surg Oncol. 2010;19(3):155-159.

140. Karlin BE, Brown GK, Trockel M, Cunning D, Zeiss AM, Taylor CB. National dissemination of cognitive behavioral therapy for depression in the Department of Veterans Affairs health care system: therapist and patient-level outcomes. J Consult Clin Psychol. 2012;80(5): $707-718$

141. Gould RL, Coulson MC, Howard RJ. Cognitive behavioral therapy for depression in older people: A meta-analysis and metaregression of randomized controlled trials. J Am Geriatr Soc. 2012; 60(10):1817-1830.

142. Linton SJ, Nordin E. A 5-year follow-up evaluation of the health and economic consequences of an early cognitive behavioral intervention for back pain: a randomized, controlled trial. Spine. 2006; 31(8):853-858.

143. Glombiewski JA, Hartwich-Tersek J, Rief W. Two psychological interventions are effective in severely disabled, chronic back pain patients: a randomised controlled trial. Int J Behav Med. 2010;17(2): 97-107.

144. Williams AC, Eccleston C, Morley S. Psychological therapies for the management of chronic pain (excluding headache) in adults. Cochrane Database Syst Rev. 2012;11:CD007407.

145. Butler AC, Chapman JE, Forman EM, Beck AT. The empirical status of cognitive-behavioral therapy: a review of meta-analyses. Clin Psychol Rev. 2006;26(1):17-31.

146. Proudfoot J, Clarke J, Birch MR, et al. Impact of a mobile phone and web program on symptom and functional outcomes for people with mild-to-moderate depression, anxiety and stress: a randomised controlled trial. BMC Psychiatry. 2013;13:312.

147. Macea DD, Gajos K, Daglia Calil YA, Fregni F. The efficacy of Webbased cognitive behavioral interventions for chronic pain: a systematic review and meta-analysis. J Pain. 2010;11(10):917-929.

148. Kerns R, Sellinger J, Goodin BR. Psychological treatment of chronic pain. Annu Rev Clin Psychol. 2011;7:411-434.

149. McCracken LM. Learning to live with the pain: acceptance of pain predicts adjustment in persons with chronic pain. Pain. 1998;74(1): 21-27.

150. Bovero A, Torta R, Ferrero A. A new approach on oncological pain in depressed patients: data from a clinical study using Brief Adlerian Psychodynamic Psychotherapy. Psychooncology. 2006;15: S1e478.

151. MacPherson H, Vickers A, Bland M, et al. Acupuncture for chronic pain and depression in primary care: a programme of research. Southampton, UK: NIHR Journals Library; 2017. Available from: https://www.ncbi. nlm.nih.gov/books/NBK409491/. Accessed March 30, 2017.

152. Hopton A, Macpherson H, Keding A, Morley S. Acupuncture, counselling or usual care for depression and comorbid pain: secondary analysis of a randomised controlled trial. BMJ Open. 2014;4(5): e004964.

153. Elkins G, Jensen MP, Patterson DR. Hypnotherapy for the management of chronic pain. Int J Clin Exp Hypn. 2007;55(3):275-287.

154. Brosse AL, Sheets ES, Lett HS, Blumenthal JA. Exercise and the treatment of clinical depression in adults. Sports Med. 2002; 32(12):741-760.

155. Baird CL, Sands L. A pilot study of the effectiveness of guided imagery with progressive muscle relaxation to reduce chronic pain and mobility difficulties of osteoarthritis. Pain Manag Nurs. 2004;5(3): 97-104.

156. Fusco M, Paladini A, Skaper SD, Varrassi G. Chronic and neuropathic pain syndrome in the elderly: Pathophysiological basis and perspectives for a rational therapy. Pain Nursing Magazine. 2014;3:94-104. 


\section{Publish your work in this journal}

Clinical Interventions in Aging is an international, peer-reviewed journal focusing on evidence-based reports on the value or lack thereof of treatments intended to prevent or delay the onset of maladaptive correlates of aging in human beings. This journal is indexed on PubMed Central, MedLine,

CAS, Scopus and the Elsevier Bibliographic databases. The manuscript management system is completely online and includes a very quick and fair peer-review system, which is all easy to use. Visit http://www.dovepress. com/testimonials.php to read real quotes from published authors. 